\title{
AMIBIASIS GENITAL EN LA NIÑA Y EN LA MUJER ADULTA
}

\author{
Dr. Alberto Duarte Contreras* \\ Dr. Ramiro Zúñiga Gamboa ** \\ Dr. Gilberto Bustamante Alvarez*** \\ Dr. Gonzalo Uribe Botero****
}

\section{INTRODUCCION}

La amibiasis genital femenina se presenta con relativa frecuencia en nuestro medio, encontrándose un mayor número de casos en las niñas que en las mujeres adultas estudiadas.

No conocemos trabajos relacionados con esta entidad en ginecología pediátrica.

\section{MATERIAL Y METODOS}

En el curso de dos años hemos estudiado ocho pacientes: cinco niñas menores de cuatro años pertenecientes a nuestra clientela particular y tres mujeres adultas de la consulta externa del Hospital San Juan de Dios de Cúcuta.

En las niñas hicimos el diagnóstico por el examen en fresco, y en algunos casos practicamos el Papanicolaou, el Shorr, el Gomori y la hematoxilina férrica de Heidenhain, con fines científicos únicamente.

En la mujer adulta rutinariamente efectuamos exámenes en fresco, coloración de Papanicolaou o de Shorr y biopsia en dos de los tres casos. (1).
A todas las pacientes les hicimos examen coprológico seriado.

\section{PATOGENIA}

La contaminación en todas nuestras pacientes seguramente fué secundaria a la amibiasis intestinal como nos lo demuestra:

a) el hallazgo de la amiba histolítica en la totalidad de los exámenes coprológicos estudiados

b) la frecuencia de coitos vaginales precedidos de coito rectal en una paciente adulta

c) las precarias condiciones higiénicas de nuestras tres pacientes adultas

d) el abandono de las madres en el cuidado y aseo de sus hijas con manifestaciones diarréicas como lo

* Médico Jefe del Departamento de Ginecología del Hospital San Juan de Dios de Cúcuta, Colombia.

** Médico Adjunto del Departamento de Obstetricia y Ginecología y Jefe del Laboratorio citohormonal del Hospital San Juan de Dios.

*** Médico Adjunto del Departamento de Pediatría del Hospital San Juan de Dios de Cúcuta.

**** Médico Jefe del Departamento de Patología del Hospital San Juan de Dios de Cúcuta. 
pudimos comprobar con un interrogatorio bien orientado

e) el hecho de haber presentado tres niñas una disentería amibiana inmediatamente anterior a la manifestación genital, y las dos restantes tener lesiones genitales concomitantes a una amibiasis intestinal aguda.

\section{HALLAZGOS CLINICOS}

Nos ha llamado la atención el hecho de que a pesar del abandono materno que hemos podido comprobar plenamente en nuestras pacientes pediátricas, se haya consultado por la infección genital amibiana muy en sus comienzos.

Sin duda alguna se debe a que el único síntoma es demasiado alarmante para la madre: pérdida hemática o hematopurulenta o hematopurulenta y necrótica genital de la niña. La queja habitual es la "aparición de una menstruación precoz, fétida y con pellejos" como lo aseveran las madres.

Por esta razón no hemos observado lesiones destructivas del himen en nuestras pequeñas pacientes.

Dada la imposibilidad de la exploración vaginal o cervical sin detrimento del himen, nos hemos queda-

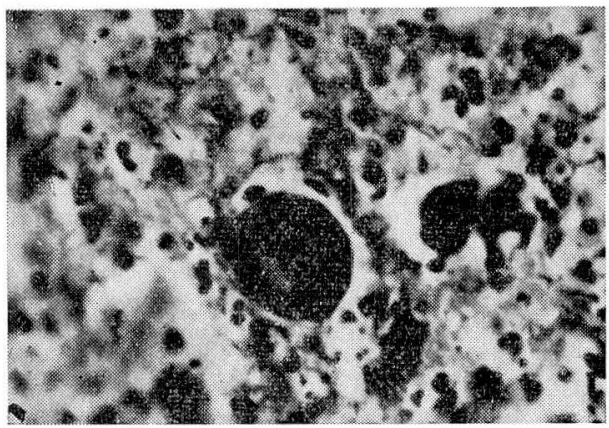

FIGURA $1-97$ X. Heidenhain.

Trofozoito de amiba en vérvix. do sin poder localizar posibles lesiones mutilantes del cérvix o de la vagina en las niñas.

En la última de nuestras pacientes infantiles que presentaba abundante pérdida hemática vaginal, iniciamos el estudio con el urocitograma, encontrando formas trofozóiticas y quísticas de la amiba en todas las preparaciones estudiadas. (2). Habría localización y lesión vesical? O solo se debería al hecho de una simple contaminación de la orina por material vaginal? Nos faltó un poco de estudio, pero haremos meticulosas y cuidadosas investigaciones al respecto para comunicarlas posteriormente.

La manifestación clínica en nuestras tres pacientes adultas ha sido flujo sanguinopurulento fétido, progresivo, con expulsión de fragmentos necróticos rodeados de mucus en etapas más avanzadas. El vaginismo ha sido un síntoma constante en nuestros casos. Se aprecia destrucción necrótica del área afectada, simulando un carcinoma, con engrosamiento inflamatorio de los parametrios cuando la localización es cervical; y se encuentran siempre trofozoitos o formas quísticas de amibas. (3) (4).

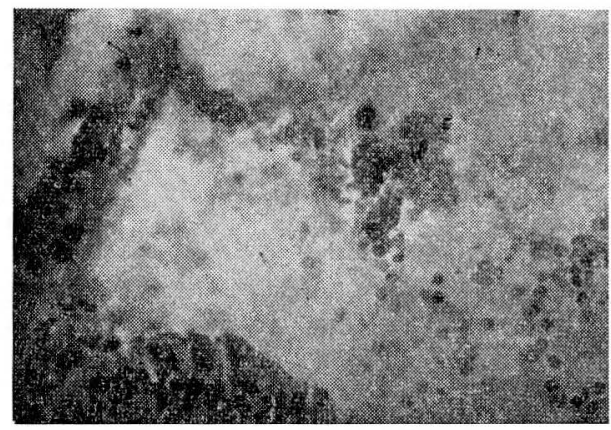

FIGURA $2-43$ X. H. E.

Quiste de amiba en cérvix. 


\section{TRATAMIENTO}

En los casos de amibiasis genital femenina hemos usado el clorhidrato de emetina a la dosis de 1 miligramo por kilo de peso y por día sin pasar de 60 miligramos en 24 horas, por un período variable de 6 a 10 días según la intensidad de los síntomas. La mejoría de las lesiones genitales es dramática con la sola aplicación de la emetina.

Pero se deben utilizar al mismo tiempo, como lo hemos practicado, las drogas disponibles por vía oral para el tratamiento de la colitis amibiana teniendo el cuidado de alternar componentes diferentes a dosis suficientes con miras a evitar recidivas o reinfecciones.

Este tratamiento lo utilizamos en las pacientes adultas y en las niñas mayores de dos años.

En una niña menor de dos años empleamos únicamente el clorohidroxiquinoleina ( $\sin$ aplicar emetina), con resultado sorprendente y satisfactorio y sin que se haya presentado recidiva hasta la fecha.

\section{CONCLUSIONES}

En vista de la relativa frecuencia de la amibiasis genital y de su facilidad para el diagnóstico, debemos tenerla siempre presente en todos los casos y en cualquier edad en que el examen revele flujo hemático 0 hematopurulento 0 hematopurulento necrótico, sin querer por esto restarle importancia a la búsqueda de las neoplasias; al contrario, queremos recordar que la infección amibiana puede implantarse sobre una neoplasia. (5) (6) (7).

Son muy importantes los cuidados higiénicos en su prevención particularmente en los casos de amibiasis intestinal en las niñas.

\section{RESUMEN}

Se presentan ocho casos de amibiasis de localización genital: cinco en niñas menores de cuatro años y tres en mujeres adultas, fácilmente diagnosticables por el examen en fresco del flujo.

La colitis amibiana concomitante fué un hallazgo constante.

La emetina tiene un efecto dramático en la curación de las localizaciones genitales.

La clorohidroxiquinoleína nos dió un resultado sorprendente en la curación de una niña menor de dos años.

\section{BIBLIOGRAFIA}

(1) MUNGUIA $\mathrm{H}$. et Al. Diagnosis of genital amebiasis in women by the standard $\mathrm{Pa}$ panicolaou technique. Amer. J. Obstet Gynec. 94: 181-8 enero 15, 66.

(2) SAYEO BA, Amin SP: Entamoeba histolytic in urine. Brit. Méd. J. $5272: 157-8$, 20 Jan 62.

(3) MANNENBERG F. D. y otros. Amoebiasis of the cervix and vagina. J. Obstet Gynec. Brit Comm. $71: 229$ 301, apr. 64.

(4) GARCIA BERBOSA J. L. Amibiasis genital femenina. Ginec. y Obstetr. de México. 20: 715-20, Jul. Ag. 65.

(5) CARDONA PEDRO NEL y col. Amibiasis genital femenina. Rev. Col. Obst. y Gin. 13: $37-45,1962$.

(6) ACEVEDO O. A., BIAGI F. y SONTOYO F. Cervico uterine amebiasis. Rev. Inst. Méd. Trop. Sao Paulo. 4:338-40, Sept. Oct. 62.

(7) RESTREPO ROBERTO y MENDEZ ALFONSO.. Infecciones amibianas confundidas con cáncer; amibiasis del cuello uterino y vagina diagnosticadas con cáncer uterino avanzado. Amibiasis de la vulva. Rev. Fac. Med. Bogotá. 16 (3): 914-20. Sept. 47. 